\title{
CINEMA INQUIETANTE: SUBLIME DE UMA SALA DE CINEMA(S) EM HERBERTO HELDER
}

\author{
Maria Inês Castro e Silva ${ }^{1}$
}

RESUMO: O presente artigo debruça-se sobre o texto "Cinemas" de Herberto Helder, publicado na edição $\mathrm{n}^{\circ} 6$ da revista «Relâmpago». A experiência do cinema como uma experiência do mundo é, em Herberto Helder, uma das faces do culto cinematográfico. A ocupação de uma cadeira de cinema pode ser o bilhete de entrada para uma experiência do transe e do arrebatamento, estes que não se excluem de uma estética do sublime.

PALAVRAS-CHAVE: cinema, sublime, transe, experiência, arrebatamento.

ABSTRACT: This article focuses on the text "Cinemas" by Herberto Helder, published in the issue No. 6 of «Relâmpago» magazine. The cinema as an experience of the world is, in Herberto Helder, one of the sides of the cinematographic cult. The occupation of a cinema seat may mean the entrance to an experience of trance and rapture and these are not excluded from the sublime aesthetics.

KEYWORDS: cinema, sublime, trance, experience, impetuousness.

Cá estou sentado
sozinho de todo
no cinema
e apetecia-me
estar morto
com lágrimas
nos olhos,
durante anos seguidos,
e os dois braços
apoiados cada um do seu lado da cadeira.
("Kino", Wolf Wondratschek)

O estabelecimento de um plano para uma posterior abordagem daquilo que ultrapassa a barreira da limitação pode transformar-se na dura demanda do abismo ou, inversamente, no melhor caminho, apontado por Nietzsche, para nos encontrarmos: “é preciso que nos saibamos perder durante um tempo se quisermos aprender alguma coisa daquilo que nós próprios não somos." (NIETZSCHE, 2000, p. 194). A entrada em Herberto Helder ou a incursão no sublime convocam-nos para a eterna volúpia do

\footnotetext{
${ }^{1}$ Trabalho desenvolvido no âmbito do Mestrado Estudos Culturais e Interartes (variante Estética Literária), no Seminário de Poéticas Comparadas, sob a orientação da Professora Doutora Rosa Maria Martelo, Faculdade de Letras da Universidade do Porto, 2010.
} 
precipício, podendo, de resto, deixar-nos emudecidos. Apesar disso, quebramos o pacto de silêncio para entrarmos no paradoxo da reflexão sobre o nosso emudecimento. Neste sentido, abordaremos a estética do sublime em "Cinemas" (1998) de Herberto Helder, equacionando a experiência da sala de cinema como experiência do mundo que não deixou indiferente a vida da poesia.

\section{I - Cinema como Experiência do Mundo}

A incursão num silêncio desarmado perante o que nos cala porque nos corta pode identificar-se com o avassalador efeito do sublime. Entrar no universo de Herberto Helder pode ter como preço a pagar o silêncio diante do que arrebata o nosso horizonte.

Atravessar as mãos de Herberto Helder é estar disposto a assistir à reinvenção de novas gramáticas e à constante, montagem, desmontagem, emenda e reorganização de textos que formam um todo contínuo, nunca passível de ser concluído. Herberto Helder é a perturbação de nunca acreditarmos num mundo como produto final e encerrado. A pujança do verbo percorre o longo fio de toda a sua obra poética, sendo muitas vezes ligado ao movimento da poesia experimental dos Anos 60, no entanto, a este respeito Manuel Gusmão diz-nos que "a sua poesia processa-se e pensa-se em termos de uma experiência da invenção verbal que excede largamente o que foi a "poesia experimental" ('concreta' ou 'visual') nos anos 60" (GUSMÃO, 2002, p. 377). A presença de Herberto Helder é de difícil catalogação num género literário, já que o presente autor parece abarcar diversas estéticas: "A riqueza da sua criação poética leva-o a ultrapassar constantemente as influências que sofre e a apresentar num mesmo poema características pertencentes a variadas estéticas" (MARINHO, 1982, p. 90). A recusa da clausura dos compartimentos leva-o a romper com uma visão da literatura dividida em géneros. É possível entender-se, em Herberto Helder, o culto de uma linguagem que não surge como linguagem segunda, transgressora de um primeiro nível de comunicação. $\mathrm{Na}$ verdade, o poético parece situar-se, em Herberto Helder, antes do mundo, tal como se assistíssemos a uma inversão dos paradigmas: "a linguagem poética não realiza a mimesis do mundo, mas que o mundo é consequência da linguagem" (EIRAS, 2004, p. 388). 
À imagem de outros poetas, Herberto Helder integra o grupo de todos aqueles que concebem o cinema como um poderoso solo a ser cultivado pela literatura. $\mathrm{O}$ cinema como transformador da imagem e, indubitavelmente, transformador da realidade caminha a par com o poder de alterar o real, subjacente à literatura.

Curiosamente, ao invés de uma prática ecfrástica de menção aos filmes, tal como, entre muitos, Manuel Gusmão procede ou, por outro lado, do recurso à transposição narrativa, Herberto Helder aponta, não só para a reflexão acerca da essência cinematográfica, como também para a experiência do cinema enquanto oportunidade para o transe fugaz: "Herberto Helder não pretende falar do cinema, mas antes dizer o que é, ou o que faz a poesia" (MARTELO, 2005, p. 50).

"Cinemas", um curto texto editado na revista Relâmpago (1998), número três, remete-nos para a estranheza do cinema, enquanto suscitador das emoções fortes. $\mathrm{O}$ texto sobre o qual nos debruçamos alude aos restritos grupos que se deslocam para a sala de cinema. Há, na verdade, um tom sectário em Helder que alude sub-repticiamente a um público-poeta que se desloca para o cinema. Se alguns, tal como José Miguel Silva ou Manuel Gusmão frequentam um cinema mais referencial que aproxima o leitor de filmes em particular, Herberto Helder paira sobre as sensações ou sobre a montagem, não permanecendo muito longe de Carlos de Oliveira e o seu "Cinema". Os poetas também vão ao cinema e escrevem sobre ele. Pese embora, a literatura e o cinema sejam dois sistemas semióticos distintos, aquela parece ter um especial apreço pelo cinema. $\mathrm{Na}$ verdade, estas duas artes não se substituem, podendo, inclusivamente, viver de forma independente uma da outra. No entanto, parece existir entre elas a especial propensão para serem equacionadas em uníssono, tema que não é, de resto, esquecido por Herberto Helder em "Cinemas". Senão, vejamos: "A escrita não substitui o cinema nem o imita, mas a técnica do cinema, enquanto ofício propiciatório, suscita modos esferográficos de fazer e celebrar" (HELDER, 1998, p. 7). Com efeito, Herberto Helder, tal como outros autores, reconhece a oportunidade de estabelecimento da estreita ligação entre a literatura e o cinema. Na verdade, estas duas artes podem, com Helder, iluminar uma das pedras de toque mais importantes entre elas: "O poema, o cinema, são inspirados porque se fundam na minúcia e rigor das técnicas da atenção ardente" (HELDER, 1998, p. 8). 
As comunidades restritas vão ao cinema para serem tocadas, para se despirem e se verem reflectidas no espelho, para serem arrebatadas e assustadas. Os atentos cinéfilos procuram morrer e ressuscitar, sempre (des)confortavelmente sentados numa cadeira de cinema.

\section{II - Cadeira de Cinema: um perigo que não vivemos verdadeiramente}

Entre a sensação do transe e a admiração pela morte catártica, Herberto Helder dá luz a "Cinemas", aproximando-se, efectivamente, da experiência do sublime. As várias reflexões em torno desta categoria fazem ressaltar como traço praticamente transversal a nomes como Longino, Edmund Burke, Immanuel Kant ou Friedrich Schiller. A aguda consciência dos corações que vibram perante o irracional ou com tudo o que não é necessariamente proporcional ou contido alerta para a implicação de subjectividade que surge, desde logo, pela admissão da admiração perante algo que não é única e exclusivamente belo.

As diferentes concepções que se alicerçam no enaltecimento de um prazer indirecto e que nem sempre é positivo dão conta da peculiaridade do Homem para se mover dentro de um inefável que o esmaga. Não se pense, porém, que o Homem mergulha no sentimento apenas com a emergência de uma modernidade, já que bem observado, o sublime exaltado no século XVIII não deixa de poder ser entendido como uma outra catarse aristotélica: "porque o reconhecimento com peripécia suscitará terror e piedade, e nós mostrámos que a tragédia é imitação de acções que despertam tais sentimentos" (ARISTÓTELES, 2003, p. 118). Burke demonstrou ser, para nós, um dos primeiros a sistematizar de forma rigorosa e detalhada o sublime, alcançando, a nosso ver, o modelo mais completo entre todas as reflexões acerca desta categoria. Todavia, a problematização do sublime parece, em todos os casos, uma compartimentação da categoria para que o Homem possa certificar-se da sua própria segurança: pormenorizar o sublime é tentar conhecê-lo até ao seu fundo para poder fugir em liberdade. Burke, em A Philosophical Enquiry into the Origin of our Ideas of the Sublime and Beautiful (1757), vai ao encontro do designado astonishment, a admiração intrínseca à contemplação de determinados objectos. Na presença deste estado de espírito, damos 
conta de uma suspensão abrupta do ânimo: "its motions are suspended, with some degree of horror" (BURKE, 1998, p. 53). Numa fase posterior, Kant acercou-se, de igual forma, desta categoria, não tendo, contudo, a disponibilidade para abarcar determinados imprevistos. De outra forma, a sua sistematização, não substituindo a rigorosidade, não parece estar disponível para responder a problemas como o feio ou o grotesco. Em Crítica da Faculdade do Juizo (1790), Kant define o sentimento do sublime como sendo

um sentimento do desprazer a partir da inadequação da faculdade da imaginação, na avaliação estética da grandeza, à avaliação pela razão e, neste caso, ao mesmo tempo um prazer despertado a partir da concordância, precisamente deste juízo da inadequação da máxima faculdade sensível, com ideias racionais (KANT, 1998, p. 153).

Schiller, um declarado discípulo de Kant, define a mesma categoria como "um objecto cuja representação leva a nossa natureza sensível a sentir os seus limites, levando porém a nossa natureza racional a sentir a sua superioridade, a sua liberdade em relação a limites" (SCHILLER, 1997, p. 143). É curioso constatar, no tom de Schiller, o bote de independência face a uma categoria que parece transcender o limite humano: "temos um impulso para preservarmos o nosso estado, para continuarmos a nossa existência, o que é denominado impulso de autoconservação" (SCHILLER, 1997, p. 143). Existe, com efeito, em Schiller, a nítida consciência de dependência face ao sublime enquanto entes sensíveis, contudo, moralmente, permanecemos detentores de uma consciência de superioridade que nos permite continuar a viver.

O estranhamento e o espanto acompanham o óculo do leitor que constata, em "Cinemas", a expressão estranha, esta que aborda, ao mesmo tempo, estranheza da sala de cinema. Na verdade, o sublime parece funcionar, não só ao nível da expressão, como também ao nível do conteúdo:

o espanto nesta poesia é também dito como terror. Mas no espaço e no movimento do mesmo poema, como em outros, o espanto pode, quase por inversão, ser o nome para o emudecimento perante o vivo, e o que diz então é o assombro, o esplendor, o êxtase, o crime (GUSMÃ̃, 2002, pp. 386-387).

Munido de um vocabulário que lhe é particular e instaurando a aura de mistério que circunda, não só a sua expressão literária, como também a sua personalidade demarcada da ribalta, Helder resgata a face recôndita do Homem que se prende com o prazer resultante de algo negativo. Herberto Helder denuncia um público que vai ao 
cinema na incessante busca "de arrebatamento, cegueira, transe" (HELDER, 1998, p. 7). $\mathrm{O}$ arrebatamento e o transe parecem apontar para uma dimensão que extravasa o limite do circunscrito. Note-se que Longino, a quem é atribuído o Tratado do Sublime, dá a conhecer a dimensão do sublime no discurso e, portanto, através de um prisma retórico. A sua concepção está, ainda, muito presa ao discurso retórico, porém, alberga já uma dimensão de elevação que tem como fim o arrebatamento:

que no Sublime consiste a suma perfeição e excelência dos discursos; (...) Porque o Extraordinário não conduz os ouvintes à persuasão, mas fora de si mesmos os arrebata, vencendo sempre o admirável com um repentino assombro quanto poderia persuadir a agradar (LONGINO, 1984, pp. 44-45).

O transe prende-se com a inquietude de um sujeito que não está a admirar o sossego, vendo-se, pelo contrário, engolido por algo que o arrebata e transcende. Quando Kant, na Crítica da Faculdade do Juizo (1790), se refere ao sublime, fixando-o como “o prazer que surge só indirectamente, ou seja ele é produzido pelo sentimento de uma momentânea inibição das forças vitais e pela efusão imediatamente consecutiva e tanto mais forte das mesmas" (KANT, 1998, p. 138) talvez autorizasse enquadrar, neste momento, o transe herberteano que nem por um momento faz com que o público abandone a irrequieta cadeira de cinema. Herberto Helder concede a um espectador do cinema a possibilidade de assistir à sua própria morte e ressurreição. $\mathrm{O}$ transe estava também ele reservado na Poética de Aristóteles: "o limite suficiente de uma tragédia é o que permite que nas acções uma após outras sucedidas, conformemente à verosimilhança e à necessidade, se dê o transe da infelicidade à felicidade ou da felicidade à infelicidade" (ARISTÓTELES, 2003, p. 116).

O presente autor inverte, em "Cinemas" a lógica da crueldade que poderia estar associada ao sublime. Com efeito, numa habitual atitude de renomeação do mundo, Herberto Helder afirma: “A beleza é a ciência cruel, imponderável, sempre fértil, da magia? Então sim, então essa energia à solta, e conduzida, é a beleza" (HELDER, 1998, p. 7).

Nas palavras de Helder parece habitar uma clara consciência do prazer que o público tem ao ver morrer-se no grande ecrã para, posteriormente, ressuscitar. Na verdade, parece alertar-nos para a possibilidade concedida pelo cinema de morrer sabendo, por certo, que depois da morte, seguir-se-á a ressurreição. O espectador morre seguro de que voltará à vida e, neste processo circular, regozija-se: "Porque as pessoas 
amam a morte, a sua morte, figurativa, figurada, figurante, e amam o restabelecimento da vida." (HELDER, 1998, p. 7). Se por um lado o abrupto sublime comporta a dimensão do assustador e arrebatador pela sua larga dimensão, exigindo o respeito ao fiel contemplador, o sujeito é capaz de discernir até onde pode arrebatar todo o perigo. Se em Longino não era verificável a dimensão do perigo de um discurso retórico, em Burke existe já uma referência ao respeito relativamente ao que nos esmaga. Senão, vejamos: "Astonishment, as I have said, is the effect of the sublime in its highest degree; the inferior effects are admiration, reverence and respect" (BURKE, 1998, p. 53). Do mesmo modo, Kant expressa a sua fidelidade ao respeito pelo sublime. No entanto, em Herberto Helder, não parecem existir alusões ao respeito, muitas vezes associado ao sublime.

O cinema torna-se, no presente autor, um momento ritual que parece assemelharse a uma dimensão carnavalesca, tão explorada por Mikhaïl Bakhtine: a possibilidade de desdobramento devolve ao calado voyeur, a possibilidade de ser, não sendo ou, se quisermos, o espectador atento torna-se espectador de si próprio, sentando-se na irrequieta cadeira de cinema para ver a sua imagem figurar. Na verdade, parece ser um outro carnaval, ao qual se refere Bakhtine, cuja barreira entre o espectador e o actor acaba, indubitavelmente por se dissolver: "le carnaval ignore tout distinction entre acteurs et spectateurs. (...) Les spectateurs n'assistent pas au carnaval, ils le vivent tous, parce que, de par son idée même, il est fait pour l'ensemble du peuple" (BAKHTINE, 1970, p. 15).

Herberto Helder não coloca de parte a escuridão sintomática de uma sala de cinema. A escuridão subjacente ao ritual da sala pode assemelhar-se à escuridão da noite: "Le cinema, d'abord, c'est la nuit. Une nuit si possible très noire, opaque, où les événements de l'ecran puissent pénétrer par les yeux ouverts (...) D'où il suit que le cinéma c'est aussi et sortout une salle o plongée dans la nuit" (apud MILNER, 2005, p. 404). A escuridão encontra-se, diversas vezes, associada ao sublime. A entrada para a sala de cinema é o lançamento solitário sobre um desconhecido que somos nós próprios. É, na verdade, a solidão pavorosa do desamparo que não deixa de nos aproximar do sublime. O eremita penetra dentro da terrível escuridão que se aproxima do sublime, entregando-se totalmente ao tribunal da imaginação: "A escuridão é terrível e precisamente por isso mesmo apropriada para o sublime. Mas ela não é terrível em si, 
mas porque nos oculta os objectos e nos entrega assim ao pleno poder da imaginação" (SCHILLER, 1997, p. 157).

O obscuro está, de igual forma, presente em Burke como elemento necessário à criação de um cenário sublime: "To make anything very terrible, obscurity seems in general to be necessary. (...) all is dark, uncertain, confused, terrible, and sublime to the last degree" (BURKE, 1998, pp. 54-55).

O texto tem o seu término com um problema que Kant coloca e que se prende justamente com o sublime como o domínio do não-representável. Admitindo Deus como uma gramática profunda, Herberto Helder coloca-O num plano transcendental que não parece passível de ser representado ao nível da imagem cinematográfica e que, de igual forma, pode identificar-se com o sublime kantiano.

Tendo em presença a máquina do cinema como uma construtora de infindáveis imagens, não podemos deixar de referir que também Herberto Helder é uma máquina de edificação da imagem poética que extrai do cinema e da vida, a terceira imagem, uma imagem poética. O cinema herberteano desloca o espectador no sentido do transe e do arrebatamento que se podem, identificar em grande medida, com uma estética do sublime. Curiosamente, o reconhecimento da nossa imperfeição plasmada no grande ecrã parece transmitir a forte impressão de esmagamento, diversas vezes alicerçado no terror. Ainda que grandioso, o sublime parece enquadrar a onda que nos engole e que mais perto se situa de nós. Se o sublime, para além do espanto, também assusta o sujeito, e, no limite pode coagi-lo ao choro (porque o Homem não deixa de se rever nele), talvez o sublime esteja mais perto do que aquilo que se possa realmente imaginar.

\section{BIBLIOGRAFIA}

ARISTÓTELES, Poética, Lisboa: Imprensa Nacional - Casa da Moeda, 2003.

ARISTÓTELES, Retórica, Lisboa: Imprensa Nacional - Casa da Moeda, 2006.

AAVV, O Bosque Sagrado; O cinema na Poesia, org. Jorge de Sousa Braga, António Ferreira, Álvaro Magalhães, s/l: Gota de Água, 1986.

BAKHTINE, Mikhaïl, L'Ouvre de François Rabelais et la Culture Populaire au Moyen Âge et sous la Renaissance, trad. Andrée Robel, França: Gallimard, 1970. 
BURKE, Edmund, A Philosophical Enquiry into the Origin of our Ideas of the Sublime and Beautiful, Nova Iorque: Oxford World's Classics, 1998.

DIOGO, Américo António Lindeza, Herberto Helder; Texto, Metáfora, Metáfora do Texto, Coimbra: Almedina, 1990.

EIRAS, Pedro Jorge Santos da Costa, Herberto Helder: Photomaton \& Vox, in $A$ Fragmentação do Sujeito na Escrita da Modernidade, Porto: Edição de Autor, 2004, pp. 379-536.

GOLDSTEIN, Laurence, The American Poet at the Movies; a Critical History, United States of America: The University of Michigan Press, 1995.

GUSMÃO, Manuel, "Herberto Helder ou „A Estrela Plenária $\square$ ", in Le Poème Continu; Somme Anthologique, Paris: Éditions Chandeigne \& Libraire Portugaise, 2002, pp. 371389.

HELDER, Herberto, “Cinemas". Relâmpago, n 3, Lisboa: 1998, pp. 7-8.

KANT, Immanuel, Crítica da Faculdade do Juizo, trad. e notas de António Marques e Valério Rohden, Lisboa: Imprensa Nacional - Casa da Moeda, 1998.

LONGINO, Tratado do Sublime, trad. Custódio José de Oliveira, Lisboa: Imprensa Nacional-Casa da Moeda, 1984.

LOPES, Silvina Rodrigues, A Legitimação em Literatura, Lisboa: Cosmos, 1994.

MARINHO, Maria de Fátima, Herberto Helder; A Obra e o Homem, Lisboa: Arcádia, 1982.

MARTELO, Rosa Maria, Os Poetas Futuros com Máquinas de Filmar nas Mãos: Relações entre Poesia e Cinema em herberto Helder e Manuel Gusmão, Rivista di Studi Portoghesi e Brasiliani, VII, Roma: Istituti Editoriali e Poligrafici Internazionali, 2005, pp. 49-61. 
MARTINS, Manuel Frias, Herberto Helder; Um Silêncio de Bronze, Lisboa: Livros Horizonte, 1983.

MILNER, Max, L'Envers du Visible; Essai sur l' Ombre, Paris: Seuil, 2005.

NIETZSCHE, Friedrich, A Gaia Ciência, trad. Alfredo Margarido, Lisboa: Guimarães Editores, 2000.

SCHILLER, Friedrich, Textos sobre o Belo, o Sublime e o Trágico, trad., Teresa Rodrigues Cadete, Lisboa: Imprensa Nacional -Casa da Moeda, 1997.

SMITH, Greg M., Film Structure and the Emotion System, Cambridge: Cambridge University Press, 2003. 